\title{
Evidence-Based Investigation for Determining the Characteristics of Knowledge Management on Organizational Innovation within Taiwanese Teaching Hospitals
}

\author{
Chien-Chang Yang ${ }^{1}$, Chen-Chung $\mathrm{Ma}^{2 *}$, Yung-Yu Su${ }^{3}$, Patricia Moulton ${ }^{4}$ \\ ${ }^{1}$ Far Eastern Memorial Hospital, Taipei, Taiwan; ${ }^{2}$ I-Shou University, Kaohsiung, Taiwan, China; ${ }^{3}$ Meiho Institute of Technology; \\ Meiho, PingTong, Taiwan, China; ${ }^{4}$ University of North Dakota, Grand Forks, USA. \\ Email: up000238@isu.edu.tw
}

Received December $13^{\text {th }}, 2010$; revised January $15^{\text {th }}, 2011$; accepted January $17^{\text {th }}, 2011$.

\begin{abstract}
Knowledge management models assist executives in generating and adopting sufficient information for managerial decision-making. These models may have utility in health care systems. This study examined knowledge management and innovation through the development of a culturally-appropriate instrument and collection of information from health care providers at several Taiwan teaching hospitals. Results indicated that several dimensions of the knowledge management model are associated with innovation and sharing of information in the study hospitals.
\end{abstract}

Keywords: Component, Evidence-Based Investigation, Knowledge Management, Organizational Innovation

\section{Introduction}

In the knowledge-based economical age, entrepreneurs who can master the information of evidence-based knowledge management will enhance their competitive advantage. This is especially important in order to ensure that new products and/or processes are innovative [1]. Healthcare organizations are facing many challenges due to the rapidly changing global healthcare system in the $21^{\text {th }}$ century. These challenges include spiraling costs, increasing demands for quality care, and patient safety issues. Health care professions are knowledge-intensive professions which place health care organizations in the position to find ways to manage their information and knowledge-bases more effectively [2].

There are various forms of knowledge: experiential (tacit), literature-based (theoretical), and evidence-based (both implicit and explicit). Experiential and literature-based knowledge, provide direction for executives in problem-solving; the process of scientific methodology can be applied to guide the process in testing whether the direction generated from experiential and literature-based knowledge is suitable for specific circumstances. As healthcare management is based on the process of scientific replication and verification of facts to generate evidence-based knowledge (EBK) [3], the development of theoretical knowledge could provide a framework for guiding evidence-based knowledge [4]

Health care executives who apply knowledge management (KM) techniques have utilized an objective method for collecting sufficient information and for generating/estimating the required supervision information for managerial decision-making within healthcare administration [5]. Evidence-based decision-making is the focus of knowledge management which "deals with critical issues of organizational adaptation, survival, and competence in a rapidly changing environment [3]."

The KM process can not only positively affect organizational innovation (OI) [6]; it has also been shown that Taiwanese business with more KM show higher capability in enhancing OI [1]. However, such evidenced-based investigation has not been conducted within the Taiwanese healthcare delivery system, especially in relationship to patient care issues and EBM in healthcare administration. As a result, there are two aims of this study: 1) creating a local culturally appropriate instrument for exploring the relationship between KM and OI for EBM; 2) recognizing the key factors of the affects of KM on OI within teaching hospitals based on the feedback of health professionals . 


\section{Background and Conceptual Framework}

There are a variety of different KM models in the literature. Gloet and Terziovski (2004) described KM processes as knowledge creation, knowledge transport, knowledge storage, knowledge distribution, and knowledge sharing [7]. Cui, Griffith, and Cavusgil (2005) indicated that KM consists of three interrelated processes: Knowledge Acquisition, Knowledge Conversion, and Knowledge Application [8]. Sandars \& Heller (2006) explained KM is the generation of knowledge, storage of knowledge, distribution of knowledge, and application of knowledge [9]. In short, KM could be regarded as an umbrella term for a variety of interlocking processes.

Effective knowledge management has been presented as one of the methods for improving innovation; as a result, innovation could be defined as a new product or service, a new production process technology or a new structure or administrative system pertaining to organizational members [1]. For understanding and identifying different types of innovation within organizations, such issue had been discussed [10]. Accordingly, the classification of innovations included technical innovation and administrative innovation [1].

Based on literature review $[6,9,11]$ and with the current challenges in the healthcare industry, this study proposed that the aspect of OI will be affected by KM directly in health care settings. Accordingly, in order to recognize the strength of relationship between the aspect of OI and $\mathrm{KM}$, a conceptual framework and a model with 10 hypotheses which was generated for achieving its study target was displayed in Figure 1.

H1: Knowledge acquires creation will affect management innovation positively.

H2: Knowledge acquires creation will affect technological innovation positively.

H3: Knowledge circulation proliferation will affect management innovation directly.

H4: Knowledge circulation proliferation will affect technological innovation directly.

H5: Knowledge storage internalize will affect management innovation directly.

H6: Knowledge storage internalize will affect technological innovation directly.

H7: Knowledge application sharing will affect management innovation directly.

H8: Knowledge application sharing will affect technological innovation directly.

H9: Management innovation will influence technological innovation directly.

H10: Technological innovation will influence management innovation directly.

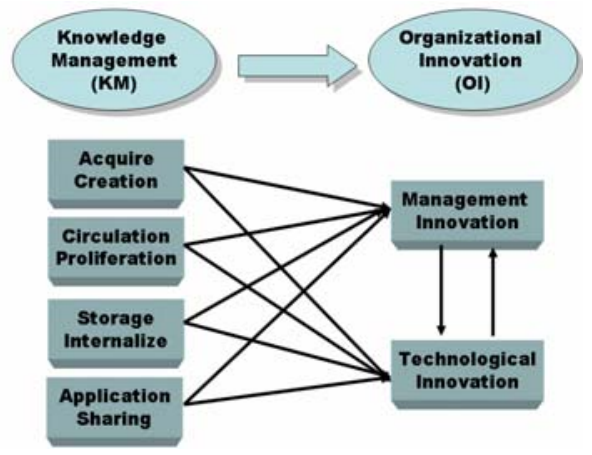

Figure 1. Conceptual framework and model.

\section{Method}

This study used a cross-sectional research design utilizing a structured questionnaire containing 55 questions with a likert-type scale from 1 (strongly disagree) to 5 (strongly agree) to recognize health professionals' (physicians, nurses, and medical technologists) opinion of KM and OI within teaching hospitals in Taiwan. The questionnaire included questions along six dimensions of knowledge management which are defined in Table 1.

In order to test the initial validity of this instrument, six domain experts were invited to discuss and revised the content of this instrument, in order to provide content validity. In addition, descriptive analysis was performed to explain the characteristics of study samples; a reliability analysis was used to explain internal consistency; and an exploratory factor analysis was used to confirm the validity of research instrument. A one-way ANOVA was used to recognize which factors of $\mathrm{KM}$ and $\mathrm{OI}$ were related to demographic variables. All these statistical procedures were performed by using SPSS 15.0 statistical software package. In addition, path analysis was adopted to explore the relationships between KM on OI (10 hypotheses) by using AMOS 7.0 statistical software package.

\section{Result}

This study was conducted at 25 teaching hospitals in Taiwan; participants were requested to fill out the survey instrument anonymously. Of the 375 questionnaires that were distributed, $228(60.8 \%)$ were completed during $1^{\text {st }}$ to $21^{\text {st }}$ October 2008. Table 2 includes detailed demographic information of participants.

The reliability analysis indicated that all of the dimensions had good internal consistency (with a Cronbach's alpha of greater than 0.8 [12] (see Table 3).

An Exploratory Factor Analysis (EFA) was utilized to examine the validity of this instrument. Questions were determined to be valid (see Table 4) (Questions would be deleted if the value of community is less than 0.4 , the value of Kaiser-Mayer-Olkin (KMO) is less than 0.70, 
Table 1. Operational definition of each dimension in this study.

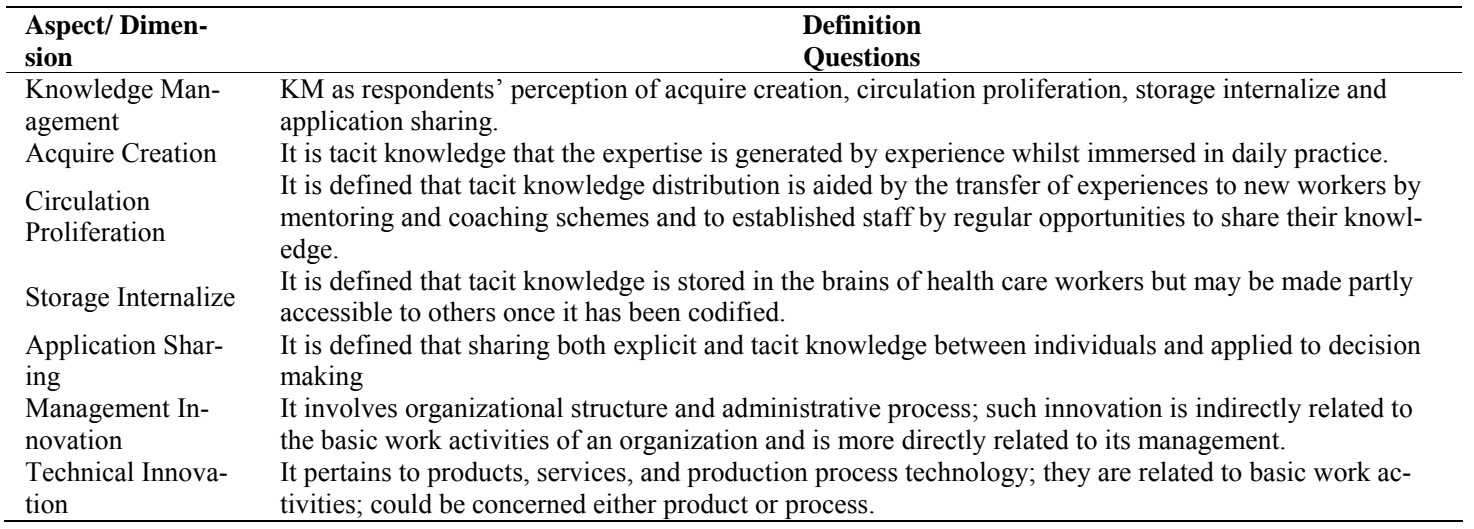

Table 2. Characteristics of participants.

\begin{tabular}{cccc}
\hline & Characteristic & Sample & Valid Percentage (\%) \\
\hline \multirow{2}{*}{ Gender } & Male & 49 & 21.5 \\
& Female & 179 & 78.5 \\
\multirow{2}{*}{ Age } & $<30$ & 58 & 25.4 \\
& $31 \sim 40$ & 106 & 46.5 \\
& $41 \sim 50$ & 56 & 24.6 \\
Education & $>51$ & 8 & 3.5 \\
& High school & 3 & 1.3 \\
& Junior college & 47 & 20.6 \\
& Bachelor & 137 & 60.1 \\
& Post-graduate & 41 & 18.0 \\
\end{tabular}

Table 3. Results of the reliability examination.

\begin{tabular}{ccccc}
\hline Dimensions & Cronbach's Alpha value & $\begin{array}{c}\text { Corrected Item-Total } \\
\text { Correlation }\end{array}$ & $\begin{array}{c}\text { Cronbach's Alpha if item } \\
\text { Deleted }\end{array}$ & $\begin{array}{c}\text { Questions } \\
\text { Q }\end{array}$ \\
Acquire Creation & 0.87 & $0.52 \sim 0.71$ & $0.84 \sim 0.86$ \\
Circulation Proliferation & 0.90 & $0.60 \sim 0.75$ & $0.87 \sim 0.88$ \\
Storage Internalize & 0.86 & $0.61 \sim 0.70$ & $0.82 \sim 0.84$ \\
Application Sharing & 0.87 & $0.53 \sim 0.73$ & $0.83 \sim 0.86$ \\
Management Innovation & 0.94 & $0.67 \sim 0.81$ & $0.92 \sim 0.94$ \\
Technological Innovation & 0.93 & $0.64 \sim 0.74$ & $0.91 \sim 0.92$ & 6 \\
\hline
\end{tabular}

Table 4. Results of the validity examination and one-way ANOVA analysis.

\begin{tabular}{|c|c|c|c|c|c|c|}
\hline \multicolumn{7}{|c|}{ Validity analysis } \\
\hline Dimensions & Communities & KMO & $\begin{array}{c}\text { Bartlett's test of } \\
\text { Sphericit }\end{array}$ & Factor Loading & $\begin{array}{c}\text { Variance Explained } \\
(\%)\end{array}$ & Eigenvalues \\
\hline A & $0.402 \sim 0.645$ & 0.83 & 0.000 & $0.634 \sim 0.808$ & 55.60 & 3.89 \\
\hline $\mathrm{C}$ & $0.625 \sim 0.682$ & 0.84 & 0.000 & $0.747 \sim 0.826$ & 63.73 & 3.19 \\
\hline $\mathrm{D}$ & $0.432 \sim 0.689$ & 0.86 & 0.000 & $0.657 \sim 0.830$ & 59.98 & 3.60 \\
\hline $\mathrm{E}$ & $0.498 \sim 0.725$ & 0.94 & 0.000 & $0.706 \sim 0.852$ & 61.33 & 7.36 \\
\hline \multicolumn{7}{|c|}{ One-way ANOVA } \\
\hline Dimensions & F valus & Sig & F valus & Sig & F valus & Sig \\
\hline A & 0.02 & 0.88 & 1.29 & 0.28 & 1.57 & 0.21 \\
\hline $\mathrm{B}$ & 0.02 & 0.88 & 1.06 & 0.37 & 1.54 & 0.22 \\
\hline $\mathrm{C}$ & 0.05 & 0.83 & 1.36 & 0.26 & 1.14 & 0.32 \\
\hline
\end{tabular}


and the value of Bartlett's Test is greater than 0.05) [13-16]. Results of the one-way ANOVA (Table 4) indicated that all dimensions of KM and OI were not significantly associated with demographic variables (gender, education, and position).

In this study, model fit of path analysis was evaluated by examining the chi-square statistic, the chi-square to degrees of freedom ratio, the comparative fit index (CFI) [16]. Goodness of Fit (GFI), Adjusted Goodness of Fit (AGFI) [17]. And the root-mean-square-error of approximation (RMSEA) [18]. Detailed examination of each hypothesis (see Table 5) indicates a significant positive association between circulation proliferation and management innovation - then list the other significant relationships (see Figure 2)

\section{Discussion}

Reliability and validity analysis indicated that the developed instrument was an appropriate tool that can be utilized for conducting studies of Taiwanese health professionals to determine the relationship between KM and OI [1-19]. This study also indicated that Management Innovation is significantly associated with Circulation Proliferation and Application Sharing. Technical Innovation is significantly associated with Circulation Proliferation, Application Sharing and the overall concept of management innovation. These results will be useful for health care administration as they explore knowledge and decision-making models for keeping up with the rapidly change of global healthcare system in the $21^{\text {th }}$ century.

The path analysis relationships results indicate that Management Innovation is a moderator variable between Circulation Proliferation, Application Sharing, and Technological Innovation. Management Innovation is indirectly related to the basic work actives of an or-

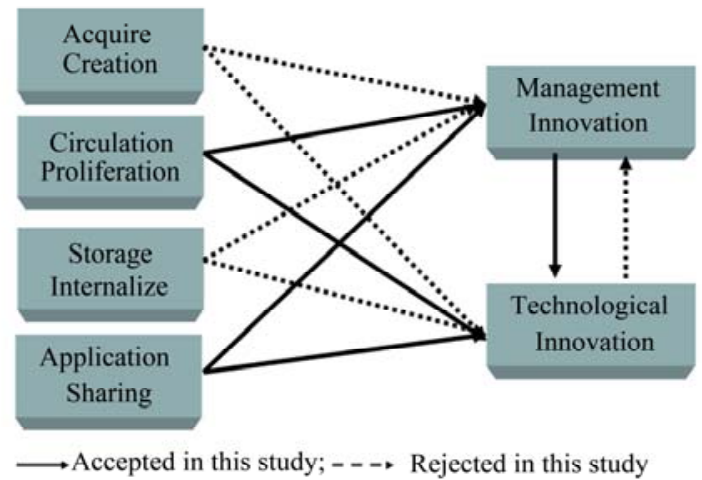

Likelihood ratio $=1.736 \mathrm{GFI}=0.990 \mathrm{AGFI}=0.948 \mathrm{CFI}=0.998$ RMSEA $=0.057$ P-Close $=0.358$

Figure 2. Results of research hypotheses.

ganization while technological innovation is directly related to basic work activities. This finding is similar to Damanpour's study that demonstrated a "dual-core model" of organizational innovation; high professionalism, low formalization, and low centralization facilitate technical innovations [10]. In short, results of this indirect relationship relates to a real-world situations within Taiwanese hospitals because all activities within hospitals are controlled by organizational structure and administrative process. These results are similar to Su's finding indicating that a hospital's net benefits will be affected by its organizational behaviors in Taiwan [22].

\section{Conclusions and Suggestion}

Based on the results of reliability and validity examination, this study provided an appropriate instrument to explore the causal relationships between KM and OI within Taiwanese hospitals for further study in healthcare industry. Moreover, the present study demonstrated that KM was a factor which will affect OI directly based on

Table 5. The results of hypotheses examination.

\begin{tabular}{ccc}
\hline Hypotheses & Standardized regression coefficient & $\begin{array}{c}\text { Critical Ratio } \\
\text { (C. R.) }\end{array}$ \\
\hline H1 & -- & -- \\
H2 & -- & - \\
H3 & $0.407^{* *}$ & 5.104 \\
H4 & $0.202^{* *}$ & 3.465 \\
H5 & -- & -- \\
H6 & -- & -- \\
H7 & $0.360^{* *}$ & 4.516 \\
H8 & $0.298^{* *}$ & 5.518 \\
H9 & $0.469^{* *}$ & 10.184 \\
H10 & -- & -- \\
$\mathrm{R}^{2}$ for Management Innovation was $0.537 ; \mathrm{R}^{2}$ for Technical Innovation was 0.777 & \\
-- Rejected in revised model; ** Statistically significant $(\mathrm{p}<\alpha=0.01)$ & \\
\hline
\end{tabular}


healthcare professionals' perspective in hospitals. The findings of this study have implications for healthcare administrators as they integrate knowledge management and organizational models that will develop learning organizations which reinforce sharing and application of knowledge throughout the hospitals.

Further research could identify whether this instrument could be used in different hospital levels or hospitals with different ownerships in Taiwan. In addition, further research could include qualitative studies to determine how hospitals are integrating knowledge management models and what successes and barriers they are experiencing.

\section{Acknowledgements}

We thank all participants who cooperated and helped us to fill out the research instrument in the sample hospitals.

\section{REFERENCES}

[1] S. H. Liao and C. C. Wu, "System Perspective of Knowledge Management, Organizational Learning, and Organizational Innovation," Expert Systems with Applications, Vol. 37, 2010, pp. 1096-1103. doi:10.1016/j.eswa.2009.06.109

[2] C. W. Choo, "Bulletin of the World Health Organization," Hershey, Idea Group Publishing, Pennsylvania, 2005.

[3] T. T. H. Wan, "Evidence-Based Health Care Management: Multivariate Modeling Approaches," Kluwer Academic Publishers, Boston, 2002.

[4] T. T. H. Wan, "Healthcare Informatics Research: From Data to Evidence-Based Management," Journal of Medical Systems, Vol. 30, 2006, pp. 3-7. doi:10.1007/s10916-006-7397-9

[5] K. J. Anne Marie, "Evidence Based Management. A Practical Guide for Health Professionals," European Journal of Orthodontics, Vol. 24, 2002, p. 526. doi:10.1093/ejo/24.5.526

[6] J. Darroch, "Knowledge Management, Innovation, and Firm Performance," Journal of Knowledge Management, Vol. 9, No. 3, 2005, pp.101-115. doi:10.1108/13673270510602809

[7] M. Gloet, and M. Terziovski, "Exploring the Relationship between Knowledge Management Practices and Innovation Performance," Journal of Manufacturing Technology Management, Vol. 15, No. 5, 2004, pp.402-409. doi:10.1108/17410380410540390

[8] A. S. Cui, D. A. Griffith and S. T. Cavusgil, "The Influence of Competitive Intensity and Market Dynamism on Knowledge Management Capabilities of MNC Subsidiaries," Journal of International Marketing, Vol. 13, No. 3, 2005, pp. 32-53. doi:10.1509/jimk.13.3.32

[9] J. Sandars and R. Heller, "Improving the Implementation of Evidence-Based Practice: A Knowledge Management Perspective," Journal of Evaluation in Clinical Practice, Vol. 12, No. 3, 2006, pp. 341-346. doi:10.1111/j.1365-2753.2006.00534.x

[10] F. Damanpour, "Organizational Innovation: A MetaAnalysis of Effects of Determinants and Moderators," Academy of Management Journal, Vol. 34, No. 3, pp. 555-590. doi:10.2307/256406

[11] R. E. McDonald and N. Srinivasan, "Technological Innovations in Hospitals: What Kind of Competitive Advantage Does Adoption Lead to?" International Journal of Technology Management, Vol. 28, No. 1, 2004, pp. 103-117. doi:10.1504/IJTM.2004.005055

[12] B. M. Byrne, "A Primer of Lisrel: Basic Applications and Programming for Confirmatory Factor Analytic Models," Springer, New York, 1989.

[13] N. Davis, "SPSS explained," P. R. Hinton, Ed., Routledge, Saunders, London, 2004.

[14] S. Marathe, T. Wan, J. Zhang and K. Sherin, "Factors Influencing Community Health Centers' Efficiency: A Latent Growth Curve Modeling Approach," Journal of Medical Systems, Vol. 31, 2007, pp. 365-374. doi:10.1007/s10916-007-9078-8

[15] B. Sahin, F. Yilmaz and K. H. Lee, "Factors Affecting Inpatient Satisfaction: Structural Equation Modeling." Journal of Medical Systems, Vol. 31, 2007, pp. 9-16. doi:10.1007/s10916-006-9038-8

[16] P. M. Bentler, "Comparative Fit Indexes in Structural Models," Psychological Bulletin, Vol. 107, 1990, pp. 238-246. doi:10.1037/0033-2909.107.2.238

[17] L. R. Tucker and C. Lewis, "A Reliability Coefficient for Maximum Likelihood Factor Analysis," Psychometrika, Vol. 38, 1973, pp. 1-10. doi:10.1007/BF02291170

[18] M. W. Browne and R. Cudeck, "Alternative Ways of Assessing Model Fit,” In: K. A. Bollen and J. S. Long, Eds., Testing Structural Equation Models, Newbury Park, Sage, 1993, pp. 136-162.

[19] B. M. Byrne, "A Primer of Lisrel: Basic Applications and Programming for Confirmatory Factor Analytic Models," Springer, New York, 1989.

[20] L. T. Hu and P. M. Bentler, "Cutoff Criteria for Fit Indexes in Covariance Structure Analysis: Conventional Criteria versus New Alternatives," Structural Equation Modeling, Vol. 6, 1999, pp. 1-55. doi:10.1080/10705519909540118

[21] J. F. J. Hair, R. E. Anderson and W. C. Black, "Multivariate Data Analysis," 5th Ed., Upper Saddle River, Prentice-Hall International, New Jersey, 1998.

[22] Y. Y. Su, K. T. Win and H. C. Chiu, "Measuring 'End-Users' Opinions for Establishing a User-Centred Electronic Health Record (EHR) System from the Perspective Of Nurses," Journal of Theoretical and Applied Electronic Commerce Research, Vol. 4, 2009, pp. 55-63. 